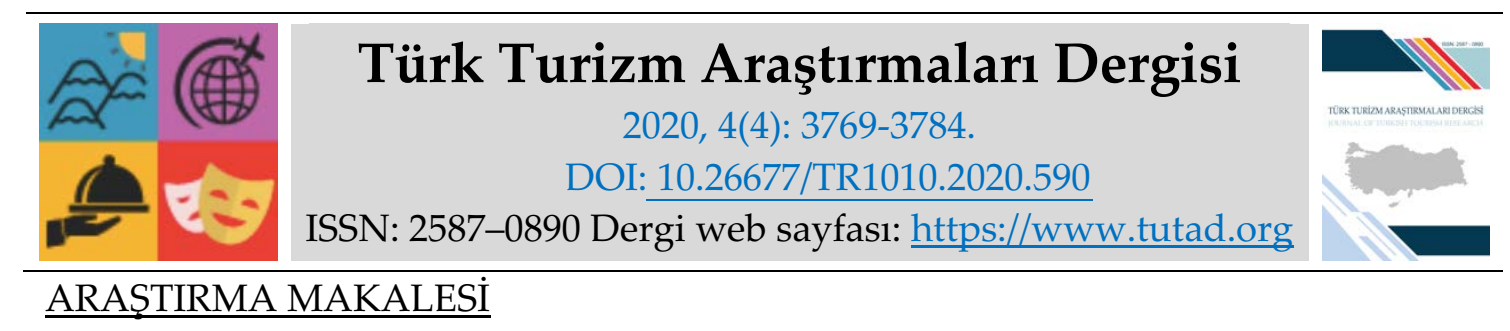

\title{
Konaklama İşletmelerinin Tavsiye Edilmesini Etkileyen Hizmetlerin Belirlenmesi: Alanya'da Bir Araştırma
}

Dr. Öğr. Üyesi Seden DOĞAN, Ondokuz Mayıs Üniversitesi, Turizm Fakültesi, Samsun, eposta: seden.dogan@omu.edu.tr ORCID: https://orcid.org/0000-0001-8547-7702

Doç. Dr. Murat Alper BAŞARAN, Alanya Alaaddin Keykubat Üniversitesi, Rafet Kayış Mühendislik Fakültesi, Antalya, e-posta: murat.basaran@alanya.edu.tr ORCID: https://orcid.org/0000-0001-9887-5531

Prof. Dr. Kemal KANTARCI, Alanya Aladdin Keykubat Üniversitesi, Turizm Fakültesi, Antalya, e-posta: kemal.kantarci@omu.edu.tr ORCID: https://orcid.org/0000-0002-9572-2959

\section{Öz}

İnternet üzerindeki çeşitli platformlarda yer alan kullanıcı değerlendirme ve puanlamalarının, diğer kullanıcıların seyahat kararı üzerindeki önemini ve etkisini ortaya koyan pek çok araştırma vardır. Söz konusu değerlendirme ve puanlamaların, konaklama işletmesinin tavsiye edilmesi üzerindeki etkisini inceleyen araştırmalar son birkaç yıldır yapılmakta olup sayısı nispeten azdır. Bu doğrultuda araştırmanın amacı HolidayCheck.de web sitesinde Alanya'da faaliyet gösteren dört ve beş yıldızlı konaklama işletmeleri için 2009-2017 yılları arasında farklı kriterler için verilen puanların, işletmelerin tavsiye edilmesi üzerindeki etki düzeyinin ve en etkili değişkenin belirlenmesidir. HolidayCheck.de web sitesinde genel durum, lokasyon, çalş̧anlar, yiyecek-içecek hizmetleri, spor-havuz-eğlence hizmetleri ve odalar olarak belirlenen altı kritere verilen puanlamalara İkili Lojistik Regresyon Analizi uygulanmıştır. Elde edilen bulgulara göre konaklama işletmelerinin tavsiye edilmesi üzerinden en yüksek etkiye sahip kriter yiyecek-içecek hizmetleri ve en düşük etkiye sahip kriter odalar olarak belirlenmiştir. İkinci derecede etkili kriter ise aile dostu, engelli dostu gibi özelliklerin puanlandığı genel durum olarak tespit edilmiştir.

* Bu makale 2016 yılında Seden Doğan (eski soyadıyla Algür) tarafından tamamlanan “Almanca Dilini Kullanan Seyahat 2.0 Kullanıcılarına Göre Otel Performans Analizi: Alanya Alan Çalışması" başlıklı doktora tezinin verileri güncellenerek üretilmiştir.

Anahtar Kelimeler: Lojistik Regresyon, Alanya, Holidaycheck, Tüketici Yorumları, Otel Puanlamaları Makale Gönderme Tarihi: 24.06.2020

Makale Kabul Tarihi: 08.10.2020

\section{Önerilen Atıf:}

Doğan, S., Başaran, M. A. ve Kantarcı, K. (2020). Konaklama İşletmelerinin Tavsiye Edilmesini Etkileyen Hizmetlerin Belirlenmesi: Alanya'da Bir Araştırma, Türk Turizm Araştırmaları Dergisi, 4(4): 3769-3784.

(C) 2020 Türk Turizm Araştırmaları Dergisi. 


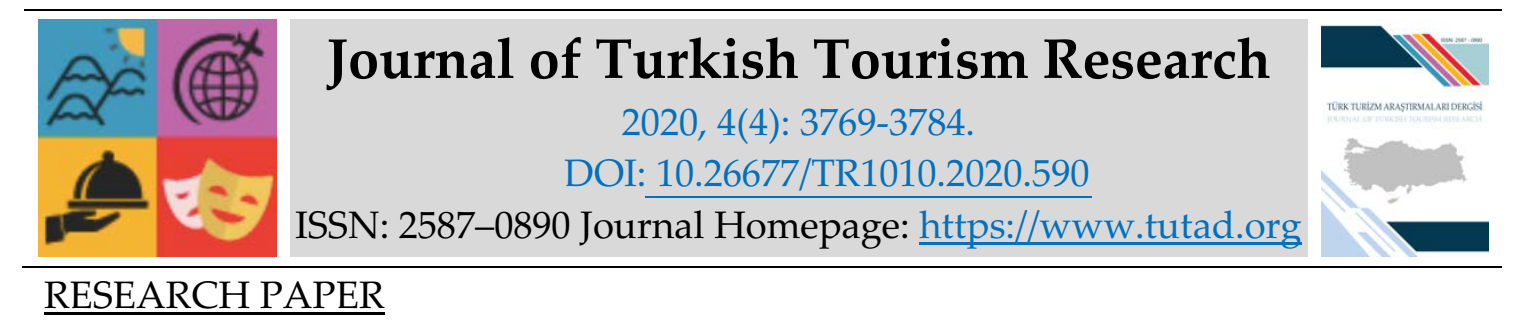

\title{
Determining the Services That Are Affective on Recommendations of Accommodation Enterprises: A Study in Alanya
}

Assistant Prof. Dr. Seden DOĞAN, Ondokuz Mayıs University, Faculty of Tourism, Samsun, email: seden.dogan@omu.edu.tr ORCID: https://orcid.org/0000-0001-8547-7702

Associate Prof. Dr. Murat Alper BAŞARAN, Alanya Alaaddin Keykubat University, Rafet Kayış Faculty of Engineering, Antalya, e-mail: murat.basaran@alanya.edu.tr

ORCID: https://orcid.org/0000-0001-9887-5531

Prof. Dr. Kemal KANTARCI, Alanya Aladdin Keykubat University, Faculty of Tourism, Antalya, e-mail: kemal.kantarci@omu.edu.tr ORCID: https://orcid.org/0000-0002-9572-2959

\begin{abstract}
There are many studies that reveal the importance and impact of user reviews and ratings on various platforms on other users' travel decision. Research examining the impact of these ratings and ratings on the recommendation of the accommodation business are being done in the past few years and the number on the research is relatively limited. Accordingly, the purpose of this research is to determine the scores given for different criteria for the four- and five-star accommodation businesses operating in Alanya on the HolidayCheck.de website between 2009-2017, the level of effect on the recommendation and the most effective variable(s). To do that, Binary Logistic Regression has been applied to the ratings for the six criteria on HolidayCheck.de which were general condition, location, staff, food \& beverage services, sportpool-entertainment and rooms. According to the results, the highest impact criterion was determined as food and beverage services and the lowest impact criterion rooms through the recommendation of accommodation establishments. The secondary effective criteria have been determined as general condition which includes child friendliness and disability friendliness.
\end{abstract}

Keywords: Logistic Regression, Alanya, Holidaycheck, Consumer Reviews, Hotel Ratings.

Received: 24.06 .2020

Accepted: 08.10.2020

\section{Suggested Citation:}

Doğan, S., Başaran, M. A. and Kantarc1, K. (2020). Determining the Services That Are Affective on Recommendations of Accommodation Enterprises: A Study in Alanya, Journal of Turkish Tourism Research, 4(4): 3769-3784.

(C) 2020 Türk Turizm Araştırmaları Dergisi. 


\section{GíRiş}

Tüketiciler bir ürün veya hizmet almadan önce çok farklı kanallardan araştırma yapmaktadır. Günümüzde bu kanallardan en çok kullanılanı internettir. Teknolojide yaşanan gelişmeler, akıllı telefonların ve sosyal ağların hayatımıza girmesiyle birlikte ağızdan ağıza iletişim olarak da ifade edilen çevrimiçi iletişim artmıştır. Çevrimiçi iletişim ile tüketiciler satın aldıkları ürün veya hizmet hakkındaki olumlu ve olumsuz görüşlerini diğer tüketicilerle paylaşmakta ve onların satın alma kararlarını etkilemektedir. Hizmet sektöründe ise bu iletişimin ayrı bir önemi vardır. Çünkü hizmet, soyut bir kavramdır ve satın almadan önce denenmesi, elle tutulup incelenmesi mümkün değildir. Bu noktada diğer tüketicilerin deneyimleri hizmetle ilgili algının oluşmasına ışık tutmaktadır. Araştırmalar tüketici tarafından yaratılan içeriğin (çevrimiçi yorumlar) satın alma kararı üzerinde pozitif etkisi olduğunu ortaya koymaktadır. Otel hizmetlerinin soyut ve daha önceden denenemez özelliğe sahip olması, buna bağlı olarak tüketicilerin risk algısının yüksek olması, tüketicileri elektronik bilgi kaynağı olarak bu yorumlara yöneltmektedir. Tüketiciler görüşlerini ve yorumlarını bloglara, tartısma forumlarına, yorum sitelerine, haber gruplarına, sosyal ağ sitelerine yazabilmektedir. Her ne kadar geleneksel ağızdan ağıza iletişim ile benzer tarafları olsa da bazı farklı boyutları bulunmaktadır. Geleneksel ağızdan ağıza iletişimin aksine elektronik ağızdan ağıza iletişim ile çok geniş mecralara hitap edilebilmektedir.

$\mathrm{Bu}$ noktadan hareketle bu araştırmada Almanca dilini konuşan turistlerin ağırlıklı olarak kullandığı HolidayCheck.de web sitesinde, Alanya'da faaliyet gösteren konaklama işletmelerinin sunduğu farklı hizmetler için verilen puanlamalar incelenmiş ve bu puanların, işletmenin tavsiye edilip edilmemesi üzerindeki etkisi belirlenmeye çalışılmıştır. İki Değişkenli Lojistik Regresyon Analizi sonucuna göre konaklama işletmelerinin sunduğu yiyecek-içecek hizmetleri misafirleri memnun ettiğinde misafirlerin bu konaklama işletmesini tavsiye etme olasılığ1 3.061 kat, konaklama işletmelerinin genel durumu misafirleri memnun ettiğinde 2.155 kat, konaklama işletmesi çalışanları misafirleri memnun ettiğinde 2.109 kat, konaklama işletmesinin spor-havuz-eğlence hizmetleri misafirleri memnun ettiğinde 1.545 kat, konaklama işletmesinin bulunduğu lokasyon misafirleri memnun ettiğinde 1.326 kat ve son olarak konaklama işletmesinin odaları misafirleri memnun ettiğinde misafirlerin bu konaklama işletmesini tavsiye etme olasılığı 1.227 kat artmaktadır. Bu sonuçlara göre altı kriter içinde konaklama işletmesinin tavsiye edilmesi üzerinden en büyük etkiye sahip kriter yiyecek-içecek hizmetleri ve en düşük etkiye sahip kriter odalar olarak belirlenmiştir.

\section{LITERATÜR TARAMASI}

\section{Konaklama İşletmelerinin Sundukları Hizmetler}

Seyahat planlaması sürecinde, hangi konaklama işletmesinde kalınacağına karar vermek oldukça önemlidir. Uzun yıllar boyunca yapılan farklı araştırmalar bu karar üzerinde farklı faktörlerin etkili olduğunu ortaya koymuştur. Ananth vd., (1992) yaptıkları araştırmada ödenen paranın değeri, lokasyon, fiyat, odalar ve ücretsiz park alanının misafirlerin işletme seçiminde dikkate aldıkları faktörler olduğunu belirlemişlerdir. Barsky'nin (1992) araştırması da bu konuda yapılan eski araştırmalardan biridir ve elde ettiği sonuçlar personelin davranışı, işletmenin yeri, odalar, fiyat, sunulan hizmetler, park alanı ve yiyecek-içecek hizmetlerinin misafirlerin memnuniyeti üzerinde etkili olduğunu ve dolayısıyla işletme seçiminde önemli olduğunu ortaya koymuştur. O yıllardan günümüze kadar yapılan araştırmalarda sonuçların tatil veya iş amaçlı seyahatler, cinsiyet, yaş gibi kriterler açısından farklılık gösterdiği görülse de misafirlerin aradığı özellikler ortaktır. 
McCleary, Choi ve Weaver (1998) iş amaçlı seyahat eden 243 Amerikalı ve 134 Koreli ile yaptıkları araştırmada her iki grup için de en önemli kriterin temizlik olduğunu belirlemişlerdir. Öte yandan Amerikalılar için önemli olan beş kriterden diğer dördü güvenlik, konforlu yatak ve yastık, personelin davranışı ve sigara içilmeyen odalar iken Koreliler için personelin davranışı, güvenlik, iş merkezlerine ve şehir merkezine mesafe ve konforlu yatak ve yastık olarak tespit edilmiştir.

Chu ve Choi (2000) 153 iş amaçlı ve 144 tatil amaçlı seyahat eden turiste yönelik yaptıkları araştırma sonucunda her iki grup için de oda, önbüro ve güvenlik kriterlerinin önemli olduğunu tespit etmişlerdir. Öte yandan Çobanoğlu vd., (2003) 612 iş amaçlı seyahat eden Türk ile yaptıkları araştırma sonucunda hizmet, fiyat ve değer, güvenlik, oda malzemeleri, teknoloji, odanın konforu, yiyecek ve içecek, ücretsiz verilen ürünler, park alanı, lokasyon, sağlık hassasiyeti ve yalnız konaklama hassasiyetinin seyahat edenlerin konaklama işletmesi seçiminde önemli olduğunu tespit etmişlerdir. İlaveten kadınlar için güvenlik, erkekler içinse yiyecek ve içecek ile ücretsiz sunulan ürünlerin daha önemli olduğu belirlenmiştir. Xue ve Cox da (2008) iş amaçlı seyahat eden Çinlilere yönelik yaptıkları araştırma sonucunda önbüro hizmetleri, imaj, güvenlik ve banyonun işletme seçiminde en önemli kriterler olduğunu tespit etmişlerdir.

Chan ve Wong (2006) 573 turiste yönelik gerçekleştirdikleri araştırma sonucunda konaklama işletmesi seçiminde fiyattan ayrı olarak lokasyon, hizmet kalitesi ve sunulan hizmetlerin çeşitliliğginin etkili olduğunu belirlemişlerdir. Emir ve Kozak (2011) Antalya'daki altı adet beş yıldızlı konaklama işletmesinde kalan 682 turiste yönelik yaptıkları araştırmanın sonucunda check-in/check-out işlemlerinin hızı, personelin güven telkin etmesi, mobilyaların kalitesi, diyet yiyecek ve içeceklerin yeterliliği faktörlerinin ön plana çıktığını tespit etmişlerdir. Baruca ve Civre (2012) Slovenya'daki 10 farklı konaklama işletmesinde kalan 733 Slovenyalı, 246 Alman, 203 İtalyan, 19 İngiliz ve 203 diğer ülke vatandaşı; toplam 1520 turiste yaptıkları anket çalışması sonucunda işletme seçimindeki en önemli kriterlerin lokasyon, arkadaş veya seyahat acentasının önerisi, fiyat, önceki deneyim, çeşitli promosyonlar ve otelin sunduğu hizmetler olduğunu belirlemişlerdir.

Ladhari (2012) son üç ay içinde Kanada'daki konaklama işletmelerinde kalan 209 turist ile yaptığ1 araştırmada resepsiyonun görselliği, rezervasyonun verimli şekilde ele alınması, personelin istek ve ihtiyaçlara hızlı karşılık vermesi, personelin kibarlığı ve personelin iletişim becerisinin önemini belirlemiştir. Sohrabi vd., (2012) Tahran'daki 19 farklı konaklama işletmesinde kalan 308 turistle gerçekleştirdikleri araştırma sonucunda işletme tercihinde lokasyon ve konfor, güvenlik ve korunma, ağ hizmetleri, atmosfer ve personelin etkili olduğunu belirlemişlerdir. Caber ve Albayrak (2014) Antalya'daki 13 farklı beş yıldızlı konaklama işletmesinde kalan 935 Alman, 716 İngiliz ve 393 Hollandalı turiste yönelik yaptıkları araştırmada Alman turistler için temizlik, personelin sıcakkanlılığı, personelin kibarlığı, yiyecek ve içecek ünitelerinin varlığı, güvenlik ve korunma; İngiliz turistler için temizlik, odanın konforu, personelin kibarlığı, otelin genel durumu, fiyat değeri; Hollandalı turistler içinse personelin sıcakkanlılığı, odanın konforu, sigara içilmeyen odaların varlığı, temizlik, hizmet hızının işletme seçiminde önemli kriterler olduğunu tespit etmişlerdir. Albayrak ve Caber (2015) Antalya'daki farklı beş yıldızlı konaklama işletmelerinde kalan 2404 Rus turist ile gerçekleştirdikleri araştırma sonucunda yiyecek ve içecek kalitesi, plaj, personel, otel ve odaların teknik durumu ve odanın dekorasyonunun işletme seçiminde etkili olduğunu belirlemişlerdir.

Yapılan literatür taraması göstermiştir ki; yıllar içerisinde yapılan farklı akademik araştırmaların sonuçlarına göre misafirlerin konaklama işletmelerinden beklentileri çok fazla değişmemiştir. Konaklama işletmesinin bulunduğu lokasyon, fiyat, çalışan personelin kalitesi, 
sunulan yiyecek ve içeceklerin çeşitliliği, güvenlik ve odalar; tatil veya iş amaçlı seyahat eden farklı demografik özelliklere sahip misafirlerin önem verdiği unsurlardır.

\section{Çevrimiçi Tüketici Değerlendirmeleri}

İnternet, turistik ürün ve hizmet sunan işletmelere önemli avantajlar yaratmaktadır. 1998-2001 yıllarında bile seyahat planları, araç kiralamaları ve otel ayarlamalarının \%54'ü için internet kullanılmıştı (Yeh, Leong, Blecher ve Lai, 2008). Turistler tatil kararı vermeden önce gideceği yerler ve rezervasyon yaptıracağı turistik işletmeler (otel, restoran, alışveriş vb.) hakkında bilgi toplamaktadır. Bu bilgi kaynakları arkadaşlar, seyahat acenteleri, broşürler, televizyon, filmler ve çeşitli rehber kitaplar olabilmektedir ancak bilgi teknolojilerinde yaşanan gelişmeler ve akıllı telefon kullanımının artmasıyla birlikte ihtiyaç duyulan bilgiye ulaşma konusunda bireylerin başvurduğu ilk kaynak internet olmaktadır (Cheng vd., 2019). Seyahat planlaması için interneti inceleyen, deneyimlerini paylaşan, seyahatle ilgili hizmetleri internet üzerinden satın alan, tüm bu işlemler için çeşitli mobil cihazlar (bilgisayar, akıllı telefon, tablet vs.) kullanan kişiler Seyahat Eden 2.0 (Traveler 2.0) olarak ifade edilmektedir. Bu kişiler, seyahat planlaması esnasında farklı ürün ve hizmetler hakkında derinlemesine araştırma ve karşılaştırmalar yapmakta ve hem planlama hem seyahat esnası hem de seyahat sonrası deneyimlerini detaylica diğer tüketicilerle paylaşmaktadırlar (Parra-Lopez, Gutierrez-Tano, Diaz-Armas ve BulchandGidumal, 2012).

Turistler tatil içerikli internet sitelerinden ve turizmle ilgili diğer sitelerden bu bilgilere kolay bir şekilde ulaşabilmekte ve bu bilgileri tatil planlamasında kullanabilmektedirler (Erol ve Hassan, 2014). Turistik ürün satın alan pek çok birey için o ürünle ilgili "kimin" "ne" söylediği büyük önem taşımaktadır. (Xie, Miao, Kuo ve Lee, 2011). Örneğin ilk defa bir destinasyona seyahat edecek kişi, seyahat planlama öncesi ve esnasında, kullanıcı tarafından yazılmış içerikleri ciddi şekilde incelemektedir (Zeng ve Gerritsen, 2014). Bu tür içerikler seyahat satın alma kararı üzerinde en etkili faktör olarak ifade edilmektedir (Amatulli de Angelis ve Stoppani, 2019; Mariani, Borghi ve Gretzel, 2019; Fang vd., 2016; Schuckert, Liu ve Law, 2014). Öyle ki, satın alma kararlarının neredeyse yarısı, bu içeriklere göre verilmektedir (Ahani vd., 2019). Seyahate çıkmayı planlayan bireylerin \%77'si her zaman veya genellikle bu içerikleri okuyarak satın alma kararı verdiklerini ifade etmiştir (Hou vd., 2019).

Çevrimiçi seyahat bilgileri ve özellikle kullanıcı tarafından yazılmış içeriğin güvenilirliği, sübjektifliği ve doğruluğu önemsenmektedir (Zeng ve Gerritsen, 2014). Çevrimiçi seyahat kanallarına yönelik yapılan bir araştırma sonucuna göre, katılımcılar diğer kullanıcıların yorumlarını güvenilir, güncellenmiş ve eğlenceli bulmaktadırlar. Ayrıca bu yorumları okuyan tatil planlayıcıları, kararlarını daha güvenle aldıklarını, riskleri azalttıklarını, belirsizlikleri yok ettiklerini, verimli bir tatil planı oluşturduklarını ve yerlerle ilgili zihinlerinde canlı imajlar oluşturarak yerle ilgili fikirler edindiklerini belirtmişlerdir (Güzel, 2014). Ayrıca konaklama işletmelerinin çeşitli özelliklerine, kullanıcıların verdikleri puanların geleneksel yıldızlama sistemine göre daha bilgilendirici ve güvenilir olduğu ifade edilmektedir (Mellinas, Nicolau ve Park, 2019). Öte yandan konaklama işletmeleri için de önemli olan husus bu içeriğin rezervasyonları nasıl etkilediğini anlamak ve bu süreci yönetme konusunda yerini belirlemektir (Sparks vd., 2011).

Kullanıcıların seyahat ve turizm içerikli paylaşımlar yaparak deneyimlerini diğer kullanıcılarla paylaştıkları platformlar arasında TravBuddy, TravelersPoint, WAYN, Woophy, Passportstamp ve TripAdvisor.com en önemli örnekler olarak kabul edilebilir. Bu platformlardan bir diğeri ise HolidayCheck'tir. Illk olarak 1999 yılında, otel tercihi yapmaya çalışan turistlere katalog bilgisinin yanında söz konusu otellerde konaklamış diğer turistlerin görüşlerinin de yer alacağı 
bir web sitesi kurma fikri ile ortaya çıkmıştır. İlk kurulan bu HolidayCheck web sitesi 2 girişimci olan Markus Schott ve Sascha Vasic için bir hobiden ibaretti. 2004 yılında ise İsviçre'de HolidayCheck firması kurulmuştur. Bu tarihten itibaren hızlı bir gelişme kaydeden firmanın uluslararası web sitesi HolidayCheck.com 2006 yılında hizmete girmiştir. 2007'de Fransızca, İspanyolca, İtalyanca, Lehçe, Rusça ve Hollandaca dilleri için de hizmet vermeye başlayan versiyonlarıyla birlikte HolidayCheck bugün 10 farklı dilde kullanılabilmektedir. Her ay 20 ila 30 milyon kişinin ziyaret ettiği HolidayCheck sitelerinde 300 binden fazla konaklama işletmesi için yazılmış 10 milyona yakın yorumu okumak mümkündür (HolidayCheck, 2019).

\section{METODOLOJi}

\section{Araştırmanın Amacı ve Önemi}

İnternet üzerindeki çeşitli platformlarda yer alan kullanıcı değerlendirme ve puanlamalarının, diğer kullanıcıların seyahat kararı üzerindeki önemini ve etkisini ortaya koyan pek çok araştırma vardır (Mellinas, Nicolau ve Park, 2019; Gao vd., 2018; Hu ve Chen, 2016; Nang Fong, Ieng Lei ve Law, 2016; Berezina vd., 2015). Bu değerlendirme ve puanlamaların, konaklama işletmesinin tavsiye edilmesi üzerindeki etkisini inceleyen araştırmalar son birkaç yıldır yapılmakta olup sayısı nispeten azdır (Liu, Chen ve Li, 2019; Nilashi vd., 2019). Bu doğrultuda bu araştırmanın amacı HolidayCheck.de web sitesinde Alanya'da faaliyet gösteren dört ve beş yıldızlı konaklama işletmeleri için 2009-2017 yılları arasında farklı kriterler için verilen puanların, işletmelerin tavsiye edilmesi üzerindeki etki düzeyinin ve en etkili değişkenin belirlenmesidir.

\section{Araştırmanın Evreni ve Örneklemi}

Alanya Akdeniz'in önemli destinasyonları arasında yer almaktadır. Alanya'da birçok plaj, koy, mağara, yayla ve ormanlık saha bulunmaktadır. Alanya'ya ilk yabancı turistlerin 1926 yılında geldiği ifade edilse de Alanya da turizmin ilk başlangıç zamanı olarak 1948-1955 yılları kabul görmektedir. Alanya'da Kültür ve Turizm Bakanlığı'ndan belgeli 300 turistik tesiste 58.526 oda bulunmaktadır. Belediye belgeli 342 tesiste 23.905 oda, bu odalarda 56.107 yatak olmak üzere toplam 642 turistik tesis bulunmaktadır. Bu tesislerde toplam 82.431 oda ve 180.563 yatak bulunmaktadır (Üngüren ve Çevirgen, 2016; Algür, 2016).

Zaman kısıtı nedeniyle araştırma evreninde yer alan tüm puanlamaların toplanması zor olduğundan araştırmada Tesadüfi Olmayan Örnekleme yöntemlerinden Kolayda Örnekleme tercih edilmiştir. Kolayda örnekleme, ana kütle içerisinden seçilecek örnek kesimin araştırmacının yargılarınca belirlendiği tesadüfî olmayan örnekleme yöntemidir. Kolayda örneklemede veriler, ana kütleden en kolay, hızlı ve ekonomik şekilde toplanmaktadır (Çeliköz ve Erişen, 2017, Firat ve Aydın, 2016; Gülertekin vd., 2016; Haşıloğlu, Baran ve Aydın, 2015). Bu doğrultuda Alanya'da faaliyet gösteren beş ve dört yıldızlı 42 adet konaklama işletmesi için 2009-2017 yılları arasında altı farklı kritere verilen puanlamalar belirlenmiştir.

Araştırmanın varsayımları şu şekildedir:

1. Alanya destinasyonu başta Almanlar ve Almanca dilini kullanan turistler tarafından yoğun olarak tercih edilen bir destinasyondur ve bu turistler, demografik özellikler bakımında kendi aralarında farklılık gösterdikleri için konaklama işletmelerini değerlendirme durumları da farklılaşmaktadır. 
2. Almanca dilini kullanan turistler, konakladıkları işletme ile ilgili değerlendirme yapmadan önce işletmede konaklamaktadırlar ve değerlendirme yapmak için HolidayCheck.de web sitesini kullanmaktadırlar.

3. HolidayCheck.de web sitesindeki değerlendirmeler, herhangi bir düzeltme ve değiştirme yapılmadan, olduğu gibi yayınlanmaktadır.

Öte yandan araştırmanın aşağıda belirtilen sınırlılıkları da mevcuttur:

1. Sadece www.HolidayCheck.de web sitesindeki puanlamalar araştırma kapsamına alınmıştır.

2. Sadece Alanya'da faaliyet gösteren 42 adet dört ve beş yıldızlı konaklama işletmesi için www. HolidayCheck.de web sitesinde altı farklı kriterlere verilen puanlar araştırma kapsamına alınmıştır.

\section{Veri Toplama Yöntem ve Aracı}

Veri toplamak için doküman incelemesi kullanılmıştır. Doküman incelemesi, hedeflenen olgu veya olgular hakkında bilgi içeren yazılı materyallerin analizini kapsamaktadır. Hangi dokümanların önemli olduğu ve veri kaynağı olarak kullanılabileceği araştırma problemi ile yakından ilgilidir (Yıldırım ve Şimşek, 2016). www.HolidayCheck.de web sitesinde konaklama işletmeleri ile ilgili yazılmış yorumlarla birlikte altı farklı kritere altı üzerinden puan verilmektedir. Bu kriterler genel durum, lokasyon, çalışanlar, yiyecek- içecek hizmetleri, sporhavuz-eğlence hizmetleri ve odalardır. Verilerin toplanması için bir değerlendirme formu oluşturulmuş, puanlamayı yapan kullanıcının cinsiyeti, yaşı, seyahat ettiği yıl, seyahat ettiği ay, seyahat edilen grup, çocuk sayısı ve konaklama süresi ile altı kritere verdiği puanlar bu formlara işlenmiştir.

\section{Araştırmanın Değişkenleri}

Araştırmada www.HolidayCheck.de web sitesinde Alanya'da faaliyet gösteren 42 adet dört ve beş yıldızlı konaklama işletmesi için çeşitli kriterlere verilen puanların, konaklama işletmesinin tavsiye edilmesi üzerindeki etki düzeyinin ve en etkili kriterin belirlenmesi amaçlanmıştır. Buna göre bağımlı değişken puanlama yapan kullanıcıların konaklama işletmesini tavsiye edip etmemesi; bağımsız değişkenler ise genel durum, lokasyon, çalışanlar, yiyecek- içecek hizmetleri, spor-havuz-eğlence hizmetleri ve odalar olarak belirlenmiştir. Tavsiye etmeme davranışı 0 (sıfır) ve tavsiye etme davranışı 1 (bir) olarak kodlanmıştır. Bağımsız değişkenlerden genel durum, lokasyon, çalışanlar, yiyecek- içecek hizmetleri, spor-havuzeğlence hizmetleri ve odalar 1-6 arasında puanlamaya sahiptir.

\section{Verilerin Analizi}

Araştırmanın amacı doğrultusunda belirlenen hipotezlerin test edilmesi için bağımlı değişken iki kategoriye sahip (evet ve hayır) değişken olduğundan İki Değişkenli (Binary) Lojistik Regresyon Analizi kullanılmıştır. Lojistik Regresyon Analizi, diğer bir adıyla Logit model, daha çok tıp alanındaki çalışmalarda kullanılan bir yöntem olmasına rağmen son yıllarda sosyal bilimler alanındaki araştırmalarda da kullanılan ileri düzey bir regresyon yöntemidir. Lojistik Regresyon Analizi, bağımlı değişkenin iki ya da çok düzeyli kategorik verilerden oluştuğu ve bağımlı değişken ile bağımsız değişkenler arasındaki neden sonuç ilişkilerinin incelendiği 
durumlarda kullanılmaktadır (Doğan ve Yağmur, 2017; Kızıloğlu vd., 2015; Büyüker İşler ve Güzel, 2014; Altunel ve Kahraman, 2012; Aksaraylı ve Saygın, 2011; Karagöz vd., 2010).

Lojistik Regresyon Analizi, temelde Regresyon Analizi olmakla birlikte bir ayırıcı analiz tekniği olma özelliğini de taşımaktadır. Bu kapsamda Regresyon Analizinden üç önemli farklılığ vardır (Şahin, 2017:650; Aktaş, 2009:110):

1. Regresyon Analizinde bağımlı değişken sayısal iken Lojistik Regresyon Analizinde kesikli bir değerdir.

2. Regresyon Analizinde bağımlı değişkenin değeri, Lojistik Regresyonda ise bağımlı değişkenin alabileceği değerlerden birinin gerçekleşme olasılı̆̆ kestirilir.

3. Regresyon Analizinde bağımsız değişkenlerin çoklu normal dağılım göstermesi koşulu aranırken, Lojistik Regresyon 'un uygulanabilmesi için bağımsız değişkenlerin dağılımına ilişkin hiçbir koşul gerekmemektedir.

İki Değişkenli (Binary) Lojistik Regresyon Analizinin temeli olasılık oranına dayanmaktadır. Olasılık oranı, bir olayın gerçekleşmesi olasılığı ile söz konusu olayın gerçekleşmemesi olasılığını karşılaştırmaktadır. Araştırmada tavsiye etmeme davranışı 0 (sıfır) ve tavsiye etme davranışı 1 (bir) olarak belirlenmiştir.

\section{BULGULAR}

Araştırma için www.HolidayCheck.de web sitesinden elde edilen veriler SPSS 24.0 programı ile analiz edilmiştir. Kullanıcılara ilişkin veriler aşağıdaki frekans tablosunda görülmektedir.

Tablo 1'de görüldügü üzere www.HolidayCheck.de web sitesinde konaklama işletmelerine puan veren kullanıcıların \%51'i kadın ve \%31'i 30 yaş altında olup \%50'si çift olarak seyahat etmiş ve \%50'si 1 hafta konaklama yapmıştır. Kullanıcıların \%25'i 2015 yılında ve \%44'ü yaz aylarında seyahat edenlerden oluşmaktadır.

Tablo 1. Kullanıcılara ait Bulgular

\begin{tabular}{lll} 
Cinsiyet & $\mathbf{n}$ & $\mathbf{\%}$ \\
\hline Erkek & 2693 & 49.1 \\
Kadın & 2791 & 50.9 \\
Yaş & $\mathbf{n}$ & $\mathbf{\%}$ \\
\hline $14-18$ & 115 & 2.1 \\
$19-25$ & 914 & 16.7 \\
$26-30$ & 676 & 12.3 \\
$31-35$ & 526 & 9.6 \\
$36-40$ & 463 & 8.4 \\
$41-45$ & 693 & 12.6 \\
$46-50$ & 675 & 12.3 \\
$51-55$ & 585 & 10.7 \\
$56-60$ & 366 & 6.7 \\
$61-65$ & 264 & 4.8 \\
$66-70$ & 146 & 2.7 \\
71 ve üzeri & 61 & 1.1 \\
Seyahat Ettiği Yil & $\mathbf{n}$ & \% \\
\hline 2017 & 59 & 1.1 \\
2016 & 158 & 2.9
\end{tabular}




\begin{tabular}{|c|c|c|}
\hline 2015 & 1391 & 25.4 \\
\hline 2014 & 923 & 16.8 \\
\hline 2013 & 943 & 17.2 \\
\hline 2012 & 718 & 13.1 \\
\hline 2011 & 429 & 7.8 \\
\hline 2010 & 538 & 9.8 \\
\hline 2009 & 325 & 5.9 \\
\hline Seyahat Ettiği Ay & $\mathbf{n}$ & $\%$ \\
\hline Ocak & 22 & 0.4 \\
\hline Şubat & 31 & 0.6 \\
\hline Mart & 91 & 1.7 \\
\hline Nisan & 221 & 4.0 \\
\hline Mayıs & 703 & 12.8 \\
\hline Haziran & 741 & 13.5 \\
\hline Temmuz & 789 & 14.4 \\
\hline Ağustos & 913 & 16.6 \\
\hline Eylül & 1046 & 19.1 \\
\hline Ekim & 713 & 13.0 \\
\hline Kasım & 163 & 3.0 \\
\hline Aralık & 51 & 0.9 \\
\hline Seyahat Edilen Grup & $\mathbf{n}$ & $\%$ \\
\hline Yalnız & 497 & 9.1 \\
\hline Çift olarak & 2713 & 49.5 \\
\hline Aile ile & 1538 & 28.0 \\
\hline Arkadaş ile & 736 & 13.4 \\
\hline Çocuk Sayısı & $\mathbf{n}$ & $\%$ \\
\hline Çocuk yok & 4080 & 74.4 \\
\hline 1 çocuk & 678 & 12.4 \\
\hline 2 çocuk & 551 & 10.0 \\
\hline 3 çocuk & 121 & 2.2 \\
\hline 4 çocuk ve daha fazla & 54 & 1.0 \\
\hline Konaklama Süresi & $\mathbf{n}$ & $\%$ \\
\hline $1-3$ gün & 48 & 0.9 \\
\hline 3-5 gün & 276 & 5.0 \\
\hline 1 hafta & 2713 & 49.5 \\
\hline 2 hafta & 2271 & 41.4 \\
\hline 3 hafta & 140 & 2.6 \\
\hline 4 hafta & 10 & 0.2 \\
\hline 5 hafta ve daha fazla & 26 & 0.5 \\
\hline TOPLAM & 5484 & 100 \\
\hline
\end{tabular}

Konaklama işletmelerinin çeşitli özelliklerinin ve sundukları hizmetlerin işletmenin tavsiye edilmesi üzerindeki etki düzeylerini belirlemek için İkili Lojistik Regresyon Analizi yapılmıştır. $\mathrm{Bu}$ analiz yapılırken bakılması gereken ilk test Hosmer -Lemeshow testidir. Modelin uyum iyiliği, bağımlı değişkeni açıklamak için oluşturulan modelin etkinliğinin bir ölçüsüdür. Modelin uyum iyiliğinin ölçüsü olarak Hosmer-Lemeshow testi ele alınmaktadır. 
Tablo 2. Hosmer-Lemeshow Testi

\begin{tabular}{|llll|}
\hline Adım & Ki-Kare & sd & Anlamlılık (p) \\
\hline 1 & 20.925 & 8 & 0.007 \\
\hline
\end{tabular}

Hesaplanan Hosmer-Lemeshow istatistiği 20.925 değeri 8 serbestlik derecesinde marjinal anlamlılık düzeyinin (olasılık değerinin) 0.007 bulunması olasılıkların uyumlu olduğunu göstermektedir (Nargeleçekenler, 2005). Kurulan lojistik regresyon modelinin doğru sınıflandırma yapılıp yapılmadığını göstermek için sınıflandırma tablosu kullanılmaktadır.

Tablo 3. Sinıflandırma Tablosu

\begin{tabular}{|c|c|c|c|c|}
\hline \multirow{2}{*}{ Gözlenen } & \multicolumn{3}{c|}{ Tahminlenen } \\
\cline { 3 - 4 } & \multicolumn{2}{|c|}{ Tavsiye Etme Davranış1 } & \multirow{2}{*}{ Doğru Tahmin } \\
\cline { 3 - 4 } & Tavsiye Etmeme & Tavsiye Etme & \\
\hline \multirow{2}{*}{$\begin{array}{c}\text { Tavsiye Etme } \\
\text { Davranış1 }\end{array}$} & Tavsiye Etmeme & 900 & 183 & 83.1 \\
\cline { 2 - 5 } & Tavsiye Etme & 124 & 4277 & 97.2 \\
\hline \multicolumn{3}{|c|}{ Genel \% } & 94.4 \\
\hline
\end{tabular}

Tablo 3'e göre modelin, puanlama yapan kullanıcıların konaklama işletmesini tavsiye etmeme davranışı göstermelerini doğru tahmin etme oranı \%83.1, tavsiye etme davranışını tahmin etme oranı ise \%97.2 olarak bulunmuştur. Modelin genel olarak doğru sınıflandırma yapma oranının \%94.4 olduğu görülmektedir.

İleri sürülen modelin katılımcılardan elde edilen veriler doğrultusunda Lojistik Regresyon Analizi yapmak için uygunluğuna karar verildikten sonra bağımsız değişkenlerin, bağımlı değişkenin açıklanmasında anlamlı olup olmadığına bakılması gereklidir. Parametrelerin sıfırdan farklılı̆̆ını sınamak amacıyla model katsayılarının anlamlılığını ölçen Omnibus testine bakılmaktadır.

Tablo 4. Model Katsayılarının Omnibus Testi (Katsayıların Anlamlılı̆̆ı)

\begin{tabular}{|lllll|}
\hline Adım 1 & Ki-Kare & sd & Anlamlılı (p) \\
\hline & Adım & 3999.794 & 7 & 0.000 \\
& Blok & 3999.794 & 7 & 0.000 \\
& Model & 3999.794 & 7 & 0.000 \\
\hline
\end{tabular}


Anlamlılık değerleri \%1 den daha düşük olduğundan; Lojistik Regresyon katsayıları aynı anda sıfıra eşit değildir. Böylece modelin \%1 seviyesinde istatistiksel olarak anlamlı olduğu söylenebilir.

Model katsayılarının anlamlı olduğu görüldükten sonra bağımlı değişkendeki değişikliklerin \%'de kaçının modelde ileri sürülen bağımsız değişkenler tarafından açıklandığına bakılması gereklidir. Bunun için aşağıdaki model özeti tablosuna bakılmaktadır. Tablo 5'e göre modelde yer alan bağımlı değişkendeki artış ya da azalışların Cox-Snell'e göre \%51.8 ve Nagelkerke'ye göre $\% 82.2$ olduğu bulunmuştur. Yani puanlama yapan kullanıcıların konaklama işletmesini tavsiye etme veya etmeme davranışının \%82.2'si modeldeki bağımsız değişkenler (genel durum, lokasyon, çalışanlar, yiyecek- içecek hizmetleri, spor-havuz-eğlence hizmetleri ve odalar) tarafından açıklanabilmektedir. O halde tavsiye etme veya etmeme davranışı üzerinde \%17.8 oranında farklı bağımsız değişkenlerin etkili olduğu söylenebilir.

Tablo 5. Model Özet Tablosu

\begin{tabular}{|cccc|}
\hline $\begin{array}{l}\text { Adım } \\
\text { Kare }\end{array}$ & -2 Log Likelihood & Cox ve Snell R Kare & Nagelkerke \\
\hline 1 & 1450.141 & 0.518 & 0.822 \\
\hline
\end{tabular}

Lojistik Regresyon Analizin bakılması gereken son tablo, parametre tahmin tablosudur. Bağımsız değişkenlerin, bağımlı değişken olarak konaklama işletmesini tavsiye etme veya etmeme davranışı üzerinde etkilerini ölçmeye yönelik olarak ileri sürülen modelden elde edilen parametre tahmini Tablo 6'da görülmektedir

Tablo 6. Parametre Tahmin Tablosu

\begin{tabular}{|l|c|c|c|c|c|c|}
\hline & $\begin{array}{c}\mathbf{( \beta )}(\mathbf{R e g} . \\
\text { K.sayıs1) }\end{array}$ & $\begin{array}{c}\text { S.E. } \\
\text { (Standart } \\
\text { Hata) }\end{array}$ & $\begin{array}{c}\text { Wald } \\
\text { İstatistiği }\end{array}$ & $\mathbf{s d}$ & $\mathbf{p}$ & $\begin{array}{c}\text { Odds } \\
\text { Oranı Exp } \\
(\boldsymbol{\beta})\end{array}$ \\
\hline Lokasyon & 0.282 & 0.076 & 13.665 & 1 & $\mathbf{0 . 0 0 0}$ & 1.326 \\
\hline Çalışanlar & 0.746 & 0.072 & 108.370 & 1 & $\mathbf{0 . 0 0 0}$ & 2.109 \\
\hline Yiyecek-İçecek Hizmetleri & 1.119 & 0.084 & 179.156 & 1 & $\mathbf{0 . 0 0 0}$ & 3.061 \\
\hline $\begin{array}{l}\text { Spor-Havuz-Eğlence } \\
\text { Hizmetleri }\end{array}$ & 0.435 & 0.076 & 32.962 & 1 & $\mathbf{0 . 0 0 0}$ & 1.545 \\
\hline Odalar & 0.205 & 0.089 & 5.339 & 1 & $\mathbf{0 . 0 2 1}$ & 1.227 \\
\hline Genel Durum & 0.768 & 0.110 & 48.422 & 1 & $\mathbf{0 . 0 0 0}$ & 2.155 \\
\hline Sabit & -13.877 & 0.555 & 624.566 & 1 & 0.000 & 0.000 \\
\hline
\end{tabular}

Tablo 6'daki $\beta$ değerleri (regresyon katsayısı) her bir bağımsız değişkenin etki katsayısını göstermektedir. Her bir bağımsız değişkenin modelde olmasının anlamlı olup olmadığı ise Wald istatistiği ile test edilmektedir. Wald istatistiğinin 2'yi geçmesi, o değişkenin önemli olduğunun göstergesidir. Tabloda $\operatorname{Exp}(\beta)$ sütununda yer alan değerler bağımsız değişkenlerin Odds oranlarını göstermektedir. Exp $(\beta)$ modeldeki diğer değişkenlerin sabit tutulması durumunda ilgili değişkenin 1 birim arttırıldığında üstünlük oranında hangi düzeyde bir artışın olacağını göstermektedir. Odds oranının yorumu kısaca özetlenecek olunursa; 1'den 
büyük bir Odds oranı olayın gerçekleşmesinin olabilirliğinin arttığını, 1'den küçük bir Odds oranı ise olayın gerçekleşmesinin olabilirliğinin azaldığını göstermektedir (Önder, 2018; Tuncer ve Kizgin, 2018:).

Tablo 6'ya göre bağımsız değişkenlerin (genel durum, lokasyon, çalışanlar, yiyecek- içecek hizmetleri, spor-havuz-eğlence hizmetleri ve odalar) konaklama işletmesinin tavsiye edilmesi üzerinde etkisi olduğu söylenebilir. Tabloya göre araştırma kapsamına alınan konaklama işletmelerinin sunduğu yiyecek-içecek hizmetleri misafirleri memnun ettiğinde misafirlerin bu konaklama işletmesini tavsiye etme olasılı̆̆ 3.061 kat, konaklama işletmelerinin genel durumu misafirleri memnun ettiğinde 2.155 kat, konaklama işletmesi çalışanları misafirleri memnun ettiğinde $2.109 \mathrm{~kat}$, konaklama işletmesinin spor-havuz-eğlence hizmetleri misafirleri memnun ettiğinde 1.545 kat, konaklama işletmesinin bulunduğu lokasyon misafirleri memnun ettiğinde 1.326 kat ve son olarak konaklama işletmesinin odaları misafirleri memnun ettiğinde misafirlerin bu konaklama işletmesini tavsiye etme olasılığı 1.227 kat artmaktadır. Elde edilen bu sonuçlar, konaklayan misafirlerin konaklama işletmelerinin sundukları hizmetlere, çalışan personelin kalitesine, işletmenin sahip olduğu çeşitli özelliklere karşı hassasiyetini ortaya koymuştur. Zira her bir kriterde yapılacak çeşitli iyileştirmeler, konaklama işletmelerinin tavsiye edilmesini pozitif şekilde etkileyecektir.

\section{SONUÇ ve TARTIŞMA}

İnternet ve sosyal medya platformları, yapısı ve işleyişi bakımından yeni bir tüketici tipi yaratmaktadır. Bu tüketici tipi özellikle davranışsal açıdan geleneksel tüketici tipine göre farklı özellikler taşımaktadır. Birbirini hiç tanımayan müşteriler alışveriş süreci ile ilgili bütün deneyim ve değerlendirmelerini birbirleri ile paylaşmakta ve satın alma süreç, seçim ve satın alma sonrası eylemlerini internet üzerinden paylaşmaktadırlar. Bireyler tatil planı yaparken 3'de 2'si misafir yorumlarını önemli bir bilgi kaynağı olarak kullanmaktadırlar. Daha önce de ifade edildiği gibi turizm hizmetinin soyut olması ve müşterilerin özelliklerine göre farklı şekilde değerlendirilebilmesi, insan odaklı olması nedeniyle daha fazla risk algısı yaratmaktadır. Bu riskin azaltılmasında misafir yorumları oldukça önemsenmektedir. Soyut bir hizmeti görmeden ve denemeden satın alma durumunda olan bir müşteri için gerçek deneyime dayalı bir yorum oldukça faydalı olarak kabul edilmektedir.

$\mathrm{Bu}$ araştırmada Alanya'da faaliyet gösteren konaklama işletmelerinin sundukları hizmetlere yönelik Holidaycheck.de web sitesinde verilen puanlamaların, işletmelerin tavsiye edilip edilmemesi üzerindeki etkisi incelenmiştir. Elde edilen bulgulara göre konaklama işletmelerinin tavsiye edilmesi üzerinden en yüksek etkiye sahip kriter yiyecek-içecek hizmetleri ve en düşük etkiye sahip kriter odalar olarak belirlenmiştir. Alanya'da faaliyet gösteren konaklama işletmelerinin büyük çoğunluğunun her şey dahil sistemiyle hizmet verdiği bilinmektedir. Bu sistem, özellikle çocuklu ailelerin gün içindeki harcamaları nedeniyle, konaklama ücretine yaklaşan ekstra ödemelerden kurtulmak amacı ile tercih edilmektedir (Üngüren, Algür ve Doğan, 2009). Bu sisteme göre sabah kahvaltısı, öğle yemeği ve akşam yemeği ile birlikte ara öğünlerde sunulan yiyecek ve içeceklerin büyük çoğunluğu, konaklama için ödenen bedele dahildir. Ana ve ara öğünlerde açık büfe sunulmaktadır. Araştırmada elde edilen sonuca göre Alanya'da faaliyet gösteren konaklama işletmeleri sundukları yiyecek ve içeceklerin çeşidi, kalitesi ve sunum şeklinde yapacakları güncellemelerle misafirlerin memnuniyetinin artmasını ve işletmeyi tavsiye etmelerini sağlayabileceklerdir. İşletmeler eğitimli ve donanımlı personel istihdam ederek ve personellerinin mutlu olmasını sağlayarak misafirlerin iyi hizmet almalarını sağlamalıdır. Örneğin Callan ve Bowman'ın (2000) yaptıkları araştırmaya göre 55 yaş üzeri turistler personelin davranışlarına daha çok dikkat etmektedirler. Alanya'nın ağırlıklı olarak 
Avrupa ülkelerinden orta yaş ve üzeri misafirlerin tercih ettiği bir turistik destinasyon olduğu düşünüldüğünde (Algür, 2016), bu destinasyondaki konaklama işletmelerinde çalışan personelin iletişim becerisi, yabancı dil bilgisi, sorun çözme başarısı ve misafirlerle olan ilişkilerinin önemi ortaya çıkmaktadır. Öte yandan işletmelerde konaklayan misafirler, sınırsız yeme-içme imkanının yanı sıra gündüz ve akşam düzenlenen eğlencelere katıldıkları için odada nispeten az vakit geçirmekte ve odayı sadece uyumak için kullanmaktadırlar. Bu noktada işletmelerin havuz, plaj, spor salonu, hamam vb. alanlarında yapacakları iyileştirmeler işletmelerin tavsiye edilmesinde olumlu etki yaratacaktır. Ancak odalarda yapacakları herhangi yeni bir düzenleme ve iyileştirme, misafir memnuniyetinin artmasına yardımcı olmakla birlikte işletmenin tavsiye edilmesi üzerinde diğer kriterlere nazaran daha az etki yaratacaktır. Öte yandan konaklama işletmesinin aile dostu ve engelli dostu olmasına yönelik özelliklerin yer aldığ 1 işletmenin genel durumu, işletmenin tavsiye edilmesi üzerinden ikinci sırada etkili olarak belirlenmiş̧ir. Aile dostu ürün veya hizmet, ortalama bir ailenin tüm üyeleri için uygun olan ürün veya hizmet olarak tanımlanmaktır. Ağırlama endüstrisinde özellikle çocuklar için özel ürün ve hizmetlerin sunulduğu konaklama işletmeleri için aile dostu olarak bahsedilmektedir (Algür, 2016). Tatil kararlarında özellikle zaman, yer, konfor ve aktivitelerde çocukların seçim rolü büyüktür. Tatillerde bazı kararlar "çocuk baskın" olarak adlandırılabilir. Ailece tatile çıkan grupların özel ihtiyaçları olabilmektedir (Çocuklar için eğlence alanları, ev hayvanlarının getirilmesine izin verilen konaklama tesisleri gibi). Birçok aile çocuklarının ihtiyaçlarına göre tatil kararı verir. Bu ihtiyaçlar çocukların yaşlarına göre değişmektedir. Bebeği olan aileler hijyen konusunda çok titiz olmaktadır. 2-5 yaş arası çocuğu olan aileler güvenlik, çocuk menüsü, çocuk oyun alanı ve çocuk bakıcısı konusunda seçici olmaktadır. 5-12 yaş aralığındaki çocuklar genelde yaşıtlarıyla birlikte oyun alanları veya yüzme havuzu gibi yerlerde oynamak istemektedirler. Bu yaş grubuna özgün animasyon gösterileri, rekreasyon olanakları onların daha mutlu bir tatil geçirmelerine yardımcı olacaktır. Engelli dostu ifadesi ise fiziksel veya zihinsel engeli olan kişilerin rahat hareket edebileceği ortamların ve fiziki imkânların varlığı için kullanılmaktadır. Konaklama işletmelerinde işletmelerin girişi, genel tuvaletler, yeme-içme üniteleri, dinlenme alanları, temalı parklar ile eğlence merkezlerinde fiziksel engeli olan turistlerin kullanımına uygun düzenlemeler yapılması gerekmektedir (Türsab, 2015). Ailesinde fiziksel engeli olan bir bireyle seyahat eden turistlerin, konaklama işletmelerini değerlendirirken bu imkânların varlığ Amadeus'un 2020 Geleceğin Seyahatçisi Raporu'na göre (2015) pek çok gelişmiş ülkede doğum oranının düşmesi ve yaşam kalitesinin yükselmesine bağlı olarak yaşlı nüfusun total nüfusa oranı yükselmektedir. 2020 yılında 65 yaş ve üzerindeki nüfus sayısı 3 katına çıkacaktır. Rapora göre her 5 Almandan biri 65 ve üzeri bir yaşta olacaktır. Alanya'ya gelen yabancı turistler içerisinde Alman turistlerin payının oldukça yüksek olduğu göz önünde bulundurulduğunda Alanya'da faaliyet gösteren konaklama işletmelerinin fiziksel olarak hareket kısıtlılığ1 yaşayan yaşlı ve engelli bireylerin rahat edebilmesi için gerekli düzenlemeleri yapmasının ne kadar önemli olduğu görülmektedir.

$\mathrm{Bu}$ araştırmanın en önemli kısıtlılıkları sadece Alanya'da faaliyet gösteren konaklama işletmelerinin örneklem olarak belirlenmesi, sadece Almanca dilini konuşan turistlerin kullandığı Holidaycheck.de web sitesindeki puanlamaların araştırma kapsamına alınması ve sadece 2009-2017 yılları arasında verilen puanların araştırmaya dahil edilmiş olmasıdır. Bundan sonra yapılacak araştırmalarda farklı turistik destinasyonlarda faaliyet gösteren konaklama işletmeleri, farklı web sitelerindeki puanlamalar ve değerlendirmeler analiz edilerek daha genellenebilir sonuçlar elde edilebilir. 


\section{KAYNAKÇA}

Ahani, A., Nilashi, M., Ibrahim, O., Sanzogni, L. and Weaven, S. (2019). Market Segmentation and Travel Choice Prediction in SPA Hotels through TripAdvisor's Online Reviews, International Journal of Hospitality Management, 80, 52-77.

Albayrak, T. and Caber, M. (2015). Prioritisation of the Hotel Attributes According to Their Influence on Satisfaction: A Comparison of Two Techniques, Tourism Management, 46, 43-50.

Algür, S. (2016). Almanca Dilini Kullanan Seyahat 2.0 Kullanıcılarına Göre Otel Performans Analizi: Alanya Alan Çalışması, Akdeniz Üniversitesi Sosyal Bilimler Enstitüsü Turizm İşletmeciliği Anabilim Dalı, Yayımlanmamış Doktora Tezi.

Amadeus, (2015). Future Traveller Tribes 2020, http://www.amadeus.com/documents/futuretraveller-tribes-2030/travel-report-future-traveller-tribes-2020.pdf Erişim Tarihi: 26.08.2020.

Amatulli, C., de Angelis, M. and Stoppani, A. (2019). Analyzing Online Reviews on Hospitality: Data-Driven Opportunities for Predicting the Sharing of Negative Emonitonal Content, Current Issues in Tourism, 22(15), 1904-1917.

Ananth, M., DeMico, F. J., Moreo, P. J., and Howey, R. M. (1992). Marketplace Lodging Needs of Mature Travelers, The Cornell H. R. A. Quarterly, August, 12-24.

Barsky, J. D. (1992). Customer Satisfaction in the Hotel Industry: Meaning and Measurement, Journal of Hospitality \& Tourism Research, 16, 51-73.

Baruca, P. Z. and Civre, Z. (2012). How do Guests Choose a Hotel?, Academica Turistica, 5(1), 7584.

Berezina, K., Bilgihan, A., Çobanoğlu, C. and Okumuş, F. (2015). Understanding Satisfied and Dissatisfied Hotel Customers: Text Mining of Online Hotel Reviews, Journal of Hospitality Marketing \& Management, 25(1), 1-24.

Caber, M. and Albayrak, T. (2014). Does the Importance of Hotel Attributes Differ for Senior Tourists? A Comparison of Three Markets, International Journal of Contemporary Hospitality Management, 26(4), 610-628.

Callan R. J. and Bowman L. (2000). Selecting a Hotel and Determining Salient Quality Attributes: A Preliminary Study of Mature British Travelers, The International Journal of Tourism Research, 2(2), 97-118.

Chan, E. S. W. and Wong, S.C. K. (2006). Hotel Selection: When Price is not the Issue, Journal of Vacation Marketing, 12, 142-159.

Cheng, X., Shixuan, F., Sun, J., Bilgihan, A. and Okumuş, F. (2019). An Investigation on Online Reviews in Sharing Economy Driven Hospitality Platforms: A Viewpoint of Trust, Tourism Management, 71, 366-377.

Chu, R. K. S. and Choi, T. (2000). An Importance-Performance Analysis of Hotel Selection Factors in the Hong Kong Hotel Industry: A Comparison of Business and Leisure Travelers, Tourism Management, 21, 363-377.

Çeliköz, M. ve Erişen, Y. (2017). EPÖ Alanında Görev Yapan Eğitim Bilimcilerin Yapılandırmacılıkla İlgili Görüssleri: Bir Karma Yöntem Araştırması, Eğitim ve Öğretim Araştırmaları Dergisi, 6(2), 286-304. 
Çobanoğlu, C., Çorbacı, K., Moreo, P. J. and Ekinci, Y. (2003). A Comparative Study of the Importance of Hotel Selection Components by Turkish Business Travelers, International Journal of Hospitality \& Tourism Administration, 4(1), 1-22.

Emir, O. and Kozak, M. (2011). Perceived Importance of Attributes on Hotel Guests' Repeat Visit Intentions, Tourism: An International Interdisciplinary Journal, 59(2), 131-143.

Erol, G. ve Hassan, A. (2014). Gençlerin Sosyal Medya Kullanımı ve Sosyal Medya Kullanımının Tatil Tercihlerine Etkisi, Uluslararası Sosyal Araştırmalar Dergisi, 7(31), 804-812.

Fang, B., Ye, Q., Kucukusta, D. and Law, R. (2016). Analysis of the Perceived Value of Online Tourism Reviews: Influence of Readability and Reviewer Characteristics, Tourism Management, 52, 498-506.

Fırat, A. ve Aydın, A. E. (2016). Hedonik ve Faydacı Alışveriş Davranışı Üzerine Bir Araştırma, Uluslararası Sosyal Araştırmalar Dergisi, 9(43), 1840-1846.

Gao, B., Li, X., Liu, S. and Fang, D. (2018). How Power Distance Affects Online Hotel Ratings: The Positive Moderating Roles of Hotel Chain and Reviewers' Travel Experience, Tourism Management, 65, 176-186.

Gülertekin Genç, S., Genç, V. ve Gümüş, M. (2016). Otel İşletmelerinde Duygusal Zekanın İş Stresi ve İş Yaşam Dengesi Üzerindeki Etkisi, Batman Üniversitesi Yaşam Bilimleri Dergisi, 6(2/1), 97-112.

Güzel, Ö. (2014). Marka İtibarını Korumada Şikâyet Takibi: Çevrimiçi Seyahat 2.0 Bilgi Kanallarında Bir Uygulama, İnternet Uygulamaları ve Yönetimi Dergisi, 5(1), 5-19.

Haşıloğlu, S. B., Baran, T. ve Aydın, O. (2015). Pazarlama Araştırmalarındaki Potansiyel Problemlere Yönelik Bir Araştırma: Kolayda Örnekleme ve Sıklık İfadeli Ölçek Maddeleri, Pamukkale İşletme ve Bilişim Yönetimi Dergisi, 2(1), 19-28.

Holiday Check. (2019). Über uns. https://www.holidaycheck.de/ueberuns, Erişim Tarihi: 26.05.2020.

Hou, Z., Cui, F., Meng, Y., Lian, T. and Yu, C. (2019). Opinion Mining from Online Travel Reviews: A Comparative Analysis of Chinese Major OTAs Using Semantic Association Analysis, Tourism Management, 74, 276-289.

Hu, Y.-H. and Chen, K. (2016). Predicting Hotel Review Helpfulness: The Impact of Review Visibility, and Interaction Between Hotel Stars and Review Ratings, International Journal of Information Management, 36, 929-944.

Ladhari, R. (2012). The Lodging Quality Index: An Independent Assessment of Validity and Dimensions, International Journal of Contemporary Hospitality Management, 24(4), 628-652.

Liu, S., Chen, Z and ve Li, X. (2019). Time-Semantic-Aware Poisson Tensor Factorization Approach for Scalable Hotel Recommendation, Information Sciences, 504, 422-434.

Mariani, M. M., Borghi, M. and Gretzel, U. (2019). Online Reviews: Difference by Submission Device, Tourism Management, 70, 295-298.

McCleary, K. W., Choi, B. M. and Weaver, P. A. (1998). A Comparison of Hotel Selection Criteria between U.S. and Korean Business Travellers, Journal of Hospitality \& Tourism Research, 22(1), 25-38.

Mellinas, J. P., Nicolau, J. L. and Park, S. (2019). Inconsistent Behavior in Online Consumer Reviews: The Effects of Hotel Attribute Ratings on Location, Tourism Management, 71, 421-427. 
Nang Fong, L. H., Ieng Lei, S. S. and Law, R. (2016). Asymmetry of Hotel Ratings on TripAdvisor: Evidence from Single- Versus Dual-Valence Reviews, Journal of Hospitality Marketing \& Management, 26(1), 67-82.

Nargeleçekenler, M. (2005). Suç Veri Tabanının Lojistik Regresyon Analizi ile Tahmini: Bursa $\begin{array}{llll}\text { Örneği. Polis Dilimleri 7(2), } & \text { Dergisi, }\end{array}$ https://arastirmax.com/en/system/files/dergiler/295/makaleler/7/2/arastirmax-suc-veritabaninin-lojistik-regresyon-analizi-ile-tahmini-bursa-ornegi.pdf

Nilashi, M., Yadegaridehkordi, E., Ibrahim, O., Samad, S., Ahani, A. and Sanzogni, L. (2019). Analysis of Travellers' Online Reviews in Social Networking Sites Using Fuzzy Logic Approach, International Journal of Fuzzy Systems, 21, 1367-1378.

Üngüren, E., Algür, S. ve Doğan, H. (2009). Konaklama ve Seyahat Acentaları Yöneticilerinin Herşey Dahil Sisteme Yönelik Tutumları: Antalya Örneği, Karamanoğlu Mehmetbey Üniversitesi Sosyal ve Ekonomik Araştırmalar Dergisi, 2, 95-112.

Parra-Lopez, E., Gutierrez-Tano, D., Diaz-Armas, R.J. and Bulchand-Gidumal, J. (2012). Travellers 2.0: Motivation, Opportunity and Ability to Use Social Media, In: M. Sigala, E. Christou, U. Gretzel (Eds). Social Media in Travel, Tourism and Hospitality: Theory, Practice and Cases, Ashgate Publishing: Farnham, UK.

Schuckert, M., Liu, X. Ve Law, R. (2014). Hospitality and Tourism Online Reviews: Recent Trends and Future Directions, Journal of Travel \& Tourism Marketing, 32, 608-621.

Sohrabi, B., Vanani, I.R., Tahmasebipur, K. v and e Fasli, S. (2012). An Exploratory Analysis of Hotel Selection Factors: A Comprehensive Survey of Tehran Hotels, International Journal of Hospitality Management, 31(1), 96-106.

Sparks B. A. and Browning V. (2011). The Impact of Online Reviews on Hotel Booking Intentions and Perception of Trust, Tourism Management, 32(6), 1310-1323.

Türsab (2015). http://www.tursab.org.tr/tr/engelsiz-turizm/dunyada-ve-turkiyede-engelsizturizm-pazari_487.html Erişim Tarihi: 26.08.2020.

Üngüren, E. ve Çevirgen, A. (2016). Alanya'daki Konaklama İşletmelerinin Genel Yapısının Analizi, Uluslararası Sosyal Araştırmalar Dergisi, 9(43), 2223-2236.

Xie, H., Miao, L. and Lee, B.Y. (2011). Consumers' Responses to Ambivalent Online Hotel Reviews: The Role of Perceived Source Credibility and Pre-Decisional Disposition, International Journal of Hospitality Management, 30, 178-183.

Xue, X. H. and Cox, C. (2008). Hotel Selection Criteria and Satisfaction Levels of the Chinese Business Traveler, Journal of China Tourism Research, 4(3-4), 261-281.

Yeh, R.J., Leong, J.K., Blecher, L. and Lai, H.H.S. (2008). Analysis of Hoteliers' ECommerce and Information Technology Applications, International Journal of Hospitality and Tourism Administration, 6(2), 29-62.

Zeng, B. and Gerritsen, R. (2014). What do We Know About Social Media in Tourism? A Review, Tourism Management Perspectives, 10, 27-36. 